\title{
The Expert System for Goods Based on Supply Chain
}

\author{
Niu Xiang-jie, Li Hua* \\ (School of Computer and Information Engineering,Beijing University of Agriculture, Beijing \\ 102206, China; School of Economics \& Management, Beijing University of Agriculture, \\ Beijing 102206, China
}

Keywords: supply chain; poultry and eggs; market price forecasting

\begin{abstract}
In the environment of supply chain, the market price of the poultry and eggs is greatly affects by different chains which increase the forecasting complexity. This paper focuses on the poultry and eggs market price forecasting methods in order to increase the predication accuracy. A market price forecasting expert system for the poultry and eggs based on neural network is proposed in this paper to build the market data system of the poultry and eggs in the supply chain. According to the neural network estimation model based on the data, the poultry and eggs market price can be accurately predicted. The experiment illustrates the improved algorithm can predicate the poultry and eggs market price in the supply chain, which can increase the accuracy and meet the practical demands in poultry and eggs market.
\end{abstract}

\section{Introduction}

With the continuous improvement of people's living standards and economic development, people's demand for poultry products is increasing ${ }^{[1]}$. In the recent years, demands for poultry and eggs also showed a significant increasing trend ${ }^{[2]}$. In the agricultural areas, the poultry and eggs market price forecasting method is an important basis for poultry and eggs production decision-making ${ }^{[3]}$. According to the predication results of the market price of poultry and eggs, it has very important economic significance to provide adequate poultry and egg products for the public $^{[4-5]}$.

In the agricultural areas, the poultry and eggs market price forecasting methods has become hot issues in the field with potentials ${ }^{[7]}$. In the supply chain environment, the market price of poultry and eggs are greatly affected by the different aspects of the supply chain which increase the complexity of the market price forecasts and reduce the market price forecasting accuracy .

In order to avoid these shortcomings, this paper proposes a poultry and eggs market price predication expert system based on neural network estimation model. The neural network estimation model based on the data in the system can forecast the poultry and eggs market prices. The experimental results show that the improved algorithm can accurately forecast the poultry and eggs price in the environment of supply chain, which can meet the actual needs of the market development.

\section{The relative theorems of the market price expert system for poultry and eggs}

In the environment of supply chain, the traditional algorithm will increase the computation complexity for the poultry and eggs market price predication if the environment is over complicated. Therefore, the poultry and eggs market price prediction expert system based on the neural network is proposed.

\subsection{Establishment of the market price data system of the poultry and eggs}

The main component analysis methods will be applied to arrange the relative data in the poultry and eggs market and extract the features to build the poultry and eggs market data system, which can provide accurate data foundation for the poultry and eggs market price prediction.

In the extraction procedure of the poultry and eggs relative data, the main component analysis method should be applied to remove the redundant data which select the main components whose eigenvalues larger than 1 or weights coefficients lager than 1 as the data variables. 
The main component analysis method use data compression and dimension reduction to analyze the data which usually applies matrix to mapping process. The method can maximize the variance of all of the components in the low-dimension space and all of the data are strongly independent. The steps for the method are as follows.

(1) Let $y_{j} \in Y, j=1,2, \cdots, N$, the vectors with different dimensions can be obtained as follows. $z_{j k}=\frac{y_{j k}-\overline{y_{k}}}{t_{k}} \in Z$

(1)

where $\overline{y_{k}}$ is the mean of the vectors of the data with different dimensions, $t_{k}$ is corresponding Standard deviation.

(2) The covariance matrix can be calculated by the following formula.

$T=\frac{1}{P}[Z-\overline{Z m})[Z-\overline{Z m}]^{U}$

where $m=[1,1, \cdots, 1]_{m \times P}, \quad \overline{z_{j}}=\frac{1}{P} \sum_{l=1}^{P} z_{j l}, \bar{Z}=\left[\overline{z_{1}}, \overline{z_{2}}, \cdots, \overline{z_{N}}\right]^{U}$;

(3) The eigenvalues can be calculated according to the poultry and eggs market price characteristic equation $(\mu m-T) V=0$.

(4) The main component in the poultry and eggs market is calculated by the following equation. $A_{k}=z_{j 1} V_{1 k}+z_{j 2} V_{2 k}+\cdots+z_{j P} V_{P} k, k=1,2, \cdots, q \leq P$

(5) According to the principles of the main component selection, the main components will contain majority of effective information with minimum of data according to the practical demands.

\subsection{Establishment of the neural network estimation model for market prices}

The market price estimation model based on neural network mainly contains input layer, hidden layer and output layer in which the hidden layer can be one tier or multiple tiers with several neurons. The S-type transformation function will be used to transfer the neurons. The following figure describes the neural network structure of the model.

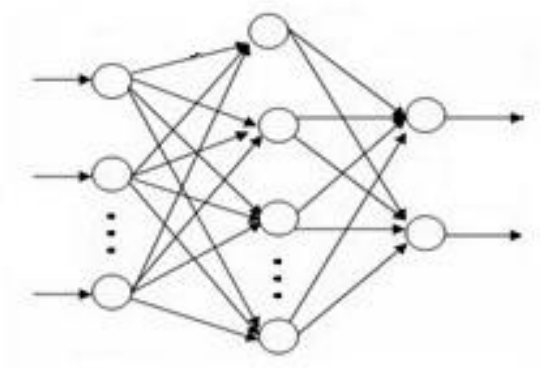

Fig. 1 The structure of the neural network estimation model for market prices

The training steps of the market price estimation model based on neural model are as follows.

(1) A value is randomly selected and it is added to the weights of different layers in order to initialize the neural network.

(2) The market price samples are inputted into the neural network model and the current input sample sequence is denoted as $Q$.

(3) The output results of $y_{k}^{\prime}$ and $z_{l}$ in the different layers from the market price estimation model based on the neural network is obtained by operations.

(4) The neurons transformation errors are calculated by the following equations. 
$\varepsilon_{k l}^{q_{1}}=\left(u_{l}^{q_{1}}-z_{l}^{q_{1}}\right) z_{l}^{q_{1}}\left(1-z_{l}^{q_{1}}\right)$

(4)

$\varepsilon_{j k}^{q_{1}}=\sum_{l=0}^{q_{1}} \varepsilon_{k l}^{q_{1}} \psi_{k l}^{\prime}(u) y_{k}^{\prime q_{1}}\left(1-y_{k}^{\prime q_{1}}\right)$

(5)

(5) The amount of trained poultry and eggs market price samples is $Q$. If $Q$ is less than the amount of total market price samples, it will return to step (2). If $Q$ is equal to the amount of total market price samples, it will go to next step.

(6) The weights and thresholds of the neural network are error compensated by the equation (4)

The poultry and eggs market prices and affect factors are pre-processed in order to obtain the sifted market price samples set. The samples are simplified in order to obtain the input data of the poultry and eggs market price estimation model based on neural network. According to the amount of neurons in the input layer and output layer in the neural network, the amount of neurons in the hidden layer can be calculated.

\section{Experimental results and analysis}

In order to verify the validity of the proposed algorithm, the experiments should be carried on. In the experiment, the poultry and eggs market prices from 01/01/2010 to 02/09/2010 are selected as the research objects. The research samples are described in the following tables

Table 1 Training samples

\begin{tabular}{cccccccc}
\hline Time & $\begin{array}{c}\text { Market } \\
\text { price }\end{array}$ & Time & $\begin{array}{c}\text { Market } \\
\text { price }\end{array}$ & Time & $\begin{array}{c}\text { Market } \\
\text { price }\end{array}$ & Time & $\begin{array}{c}\text { Market } \\
\text { price }\end{array}$ \\
\hline 1.1 & 43 & 1.11 & 74 & 1.21 & 99 & 1.31 & 46 \\
1.2 & 44 & 1.12 & 56 & 1.22 & 89 & 2.1 & 45 \\
1.3 & 51 & 1.13 & 34 & 1.23 & 87 & 2.2 & 74 \\
1.4 & 62 & 1.14 & 84 & 1.24 & 59 & 2.3 & 84 \\
1.5 & 72 & 1.15 & 76 & 1.25 & 45 & 2.4 & 46 \\
1.6 & 45 & 1.16 & 26 & 1.26 & 88 & 2.5 & 47 \\
1.7 & 62 & 1.17 & 37 & 1.27 & 49 & 2.6 & 37 \\
1.8 & 74 & 1.18 & 15 & 1.28 & 64 & 2.7 & 49 \\
1.9 & 84 & 1.19 & 64 & 1.29 & 18 & 2.8 & 57 \\
1.10 & 32 & 1.20 & 19 & 1.30 & 37 & 2.9 & 67
\end{tabular}

The performance of the proposed algorithm is verified using Support Vector Machine, price model, rough set algorithm and neural network estimation algorithm. The predication results in the previous 10 days are compared with the actual prices in order to obtain the performance of the different forecasting methods.

Table 2 Predication results of different algorithms

\begin{tabular}{cccccc}
\hline Time & $\begin{array}{c}\text { Actual } \\
\text { value }\end{array}$ & $\begin{array}{c}\text { Support Vector } \\
\text { Machine }\end{array}$ & $\begin{array}{c}\text { Price } \\
\text { model }\end{array}$ & $\begin{array}{c}\text { Rough set } \\
\text { algorithm }\end{array}$ & $\begin{array}{c}\text { Neural Network estimation } \\
\text { algorithm }\end{array}$ \\
\hline 1.1 & 4.1 & 3.9 & 4.2 & 3.8 & 4.2 \\
1.2 & 4.5 & 4.5 & 4.6 & 4.4 & 4.6 \\
1.3 & 5.7 & 5.6 & 5.8 & 5.8 & 5.6 \\
1.4 & 6.2 & 6.3 & 6.4 & 6.3 & 6.3 \\
1.5 & 5.4 & 4.9 & 4.5 & 4.9 & 5.6 \\
1.6 & 3.7 & 3.1 & 4.3 & 3.4 & 3.5 \\
1.7 & 6.8 & 6.1 & 6.6 & 6.4 & 7.6 \\
1.8 & 7.4 & 6.8 & 6.5 & 6.8 & 8.4 \\
1.9 & 8.5 & 7.9 & 7.4 & 7.6 &
\end{tabular}


According to the previous table, the results from the obtained neural network estimation algorithm are close to the actual prices in the poultry and eggs market with minimum errors. For other 3 estimation methods, the results for the previous 4 days have high accuracy while the accuracy is greatly reduced in the fifth day.

\section{Conclusions}

The traditional algorithms have the defects of increasing complexity for the market price forecasting due to the market prices of the poultry and eggs are greatly affected by the different chains in the supply chain. In order to solve the defects, the paper proposes a poultry and eggs market price forecasting expert system based on the neural network in which the market data system for the poultry and eggs is established in the supply chain. The neural network estimation model is build based on the data system which can forecast the market price of the poultry and eggs. The experiments illustrate the improved algorithm can accurately predict the poultry and eggs price in the supply chain, which can meet the practical demands.

\section{Fund:}

1.Modern agricultural industry technology system, Peking Poultry innovation team.(5075299025)

2. The Study on the balance of the supply and demand of poultry products. (2044115113)

\section{References}

[1] Gorokhov A, Linnartz J P. Robust OFDM receivers for dispersive time-varying channels: equalization and channel acquisition [J]. IEEE Trans, Commun, 2004,52(4): 572-583.

[2] Krieger G, Papathanassiou K P, Cloude S R. Spaceborne Polarimetric SAR Interferometry: Performance Analysis and Mission Concepts[J]. EURASIP J. Appl. Signal Process. 2005(20): 3272-3292.

[3] Y. Zuo, E. Kita, Stock price forecast using Bayesian network [J]. Expert Systems with Applications, 2012, 39(8), 6729-6737.

[4] Papathanassiou K P, Cloude S R. Single-baseline polarimetric SAR interferometry[J]. IEEE Trans. Geosci. Remote Sens. 2001, 39(11): 2352-2363.

[5] Cloude S R, Papathanassiou K P. Three-stage inversion process for polarimetric SAR interferometry[J]. IEE Proc.-Radar Sonar Navig. 2003, 150(3): 125-134. 